\title{
Changes in detrusor excitability and C-kit, connnexin- 43 expression in rats after spinal cord injuries
}

\author{
Hua-mao Jiang ${ }^{* 1}$, Shu-bin $\mathrm{Si}^{1}$, Shuqi $\mathrm{Du}^{2}$, Zhenhua $\mathrm{Li}^{2}$, De-wang $\mathrm{Fu}^{1}$, Xiao-peng Wang ${ }^{1}$ and \\ Bin Song ${ }^{1}$
}

\author{
${ }^{1}$ Urology Surgery, the First Hospital Affiliated of Liaoning Medical College, Jinzhou, 121001, China. \\ ${ }^{2}$ Urology Surgery, the First Hospital Affiliated of China Medical University, Shenyang, 110001, China
}

Accepted 9 October, 2012

\begin{abstract}
The current study aims to explore the possible correlations between detrusor excitability and the expression of C-kit and connexin-43 (Cx43). Fifty-two adult female Sprague Dawley (SD) rats were randomly divided into the normal control (NC), supra-sacral cord injury (SSCl) and sacral cord injury (SCl) groups. Neurogenic bladder models were established. Urodynamic examination, bladder pathological observation and detrusor muscle excitability detection were performed. Meanwhile, the expression of C-kit and Cx43 was detected using immunohistochemistry and Western blot analysis. The detrusor leak point pressure of the $\mathrm{SSCl}$ group increased significantly compared to the NC group, whereas that of the $\mathrm{SCl}$ group decreased significantly. The spontaneous detrusor muscle contraction frequency of the SSCl group increased significantly compared to the $\mathrm{NC}$ group, whereas that of the $\mathrm{SCl}$ decreased significantly. The C-kit and Cx43 positive expression in the SSCl was significantly higher than that in the control group, whereas that in the $\mathrm{SCl}$ group was significantly lower $(P<0.01)$ The $C$-kit and $\mathrm{Cx} 43$ protein content in the $\mathrm{SSCl}$ group was significantly higher compared to the NC group, whereas that in the SCl group was significantly lower $(P<0.01)$. Changes in excitability and the expression of C-kit and Cx43 expression contribute to the occurrence of detrusor hyperreflexia and areflexia.
\end{abstract}

Key words: Spinal cord injuries, detrusor hyperreflexia, detrusor areflexia, urodynamics, C-kit, connexin-43.

\section{INTRODUCTION}

Neurogenic bladder (NGB) is a common type of bladder dysfunction in clinic. Spinal cord injury is one of the most common factors which can cause NGB. Spinal cord injury mainly includes sacral cord injury (SCI) and supra-sacral cord injury (SSCl). SCl can lead to detrusor areflexia (DA), whereas $\mathrm{SSCl}$ can cause detrusor hyperreflexia (DH) (Biering-Sorensen et al., 2008). However, the pathologic mechanism of $\mathrm{DA}$ and $\mathrm{DH}$ still remains controversial. As one of the mainstream theories in this respect, the myogenic theory holds that the change in detrusor excitability is an important mechanism of DA and DH (Pannek et al., 2008). Nowadays, scholars have widely accepted that spontaneous contractions of the

\footnotetext{
*Corresponding author. Email: huamaojiang@126.com. Tel: 86-
} 416-4197637. Fax: 86-416-4197637. smooth muscle in the gastrointestinal tract are associated with Cajal interstitial cells in the gastrointestinal wall. Cajal cells have a pacing function. They produce waves of depolarization which are transferred to the smooth muscle cells through gap junctions to induce the generation of action potentials. Gap junctions are mainly composed of connexins, among which connexin-43 (Cx43) is an important one. A change in the Cx43 expression can reflect a change in the gap junctions (O'Carroll et al., 2008). The same Cajal-associated mechanism is also very likely to happen in other organs. Meanwhile, Cajal cells express C-kit receptors (tyrosine kinase receptors) specifically, thus, C-kit can serve as the important marker for Cajal cells. In the current study, we detected the expression of $\mathrm{C}$-kit and $\mathrm{C} \times 43$ in the bladder with $\mathrm{DA}$ and $\mathrm{DH}$, and also explored the correlations between the expression of C-kit and Cx43 and the pathologic mechanism of NGB. 


\section{MATERIALS AND METHODS}

\section{Animal grouping}

Fifty-two adult female SD rats were selected. They were randomly divided into the normal control (NC, $n=12$ ), supra-sacral cord injury (SSCI, $n=20$ ) and sacral cord injury ( $\mathrm{SCl}, \mathrm{n}=20$ ) groups. This study was carried out in strict accordance with the recommendations in the Guide for the Care and Use of Laboratory Animals of the National Institutes of Health. The animal use protocol has been reviewed and approved by the Institutional Animal Care and Use Committee (IACUC) of the First Hospital Affiliated of Liaoning Medical College.

\section{Model preparation}

Rats were anesthetized with an intraperitoneal injection of $10 \%$ chloral hydrate $(\mathrm{CH}, 0.03 \mathrm{ml} / \mathrm{kg}) . \mathrm{T}_{13}$ was connected with the thirteenth floating rib as the bony landmark, a $2 \mathrm{~cm}$ longitudinal incision was cut on the back, and subcutaneous blunt dissection was performed. The paraspinal muscle was longitudinally cut open with the blade against both sides of the acantha. The vertebral lamina of L1-2 was cut off up to the root of the transverse process. The dura mate was cut open and spinal cord transection was performed with the blade. Gelatin sponge was stuffed between the broken ends. The layers were closed subsequently after hemostasis. The rats were given intraperitoneal injection of gentamicin for consecutive seven days after surgery $(5000 \mathrm{U} / \mathrm{kg}$, qd).

$\mathrm{S} 1-2$, the acantha and vertebral lamina were exposed after blunt dissection. The acantha and vertebral lamina of L7-S1 were cut off with a laminectomy rongeur. After the dura mate was exposed, the dura mate and spinal cord were transected with ophthalmic scissors. Other procedures were the same as those done for the $\mathrm{SSCl}$ group. The NC group did not receive any treatment. The rats were fed in separated cages after surgery. They were helped to urinate and defecate by pressing upon the body surface above the bladder three times a day using the Crede maneuver.

\section{Urodynamic detection}

Urodynmic detection was carried out four weeks later. The rats were anaesthetized with $10 \% \mathrm{CH}(0.03 \mathrm{ml} / \mathrm{kg})$. A lower abdominal incision was made. An epidural catheter connected with a pressure detection catheter was inserted into the bladder from the top. This epidural catheter was, respectively connected to an urodynamometer and microperrfusion pump through a three-limb tube. Filling cystometry was performed at a water flushing speed of $0.2 \mathrm{ml} / \mathrm{min}$. Bladder compliance was calculated as follows: the bladder compliance $=$ the priming volume/the detrusor leak point pressure. According to the results, experimental $\mathrm{DH}$ and $\mathrm{HA}$ rats were screened out.

\section{In vitro mechanical traction and stimulation}

The whole bladder was cut off and then cultured in Kerb solution at $4^{\circ} \mathrm{C}$. Some $10 \times 3 \times 3 \mathrm{~mm}$ bladder strips were prepared. Both ends of the strip were ligated, with one end connected to a readjusting bolt through the small hook at the base of the organ chamber and the other end to the sensing head of a tension transducer. The chamber was filled up with Kerb solution ventilated with $95 \% \mathrm{O}_{2}$ and $5 \% \mathrm{CO}_{2}$ at $37^{\circ} \mathrm{C}$. The parameters of the measuring software were set as follows: a tension model, the scanning speed at $10 \mathrm{~s} /$ div, the sensitivity at $0.75 \mathrm{~g}$, constant concurrent time; the sampling frequency at $400 \mathrm{~Hz}$, and the filtering frequency at $30 \mathrm{~Hz}$. The tension-free strip was dragged gradually with the readjustment of the bolt. The minimum tension at the time of contraction occurrence was recorded. The tension reflects the excitation threshold of the detrusor to stimulation.

The bolt was readjusted until the tension of the strip rose up to $1.25 \mathrm{~g}$. The contraction frequency was then detected. A higher frequency suggests a higher excitability of the detrusor.

\section{Immunohistochemistry}

Sections (5 $\mu \mathrm{m}$ thick) were deparaffinized with xylene, rehydrated and incubated with fresh $0.3 \%$ hydrogen peroxide in methanol for $30 \mathrm{~min}$ at room temperature. Specimens were rehydrated through a graded ethanol series and washed in phosphate-buffered saline (PBS). Sections were then washed with PBS and incubated in secondary antibody for $30 \mathrm{~min}$ at room temperature. The tissue sections were lightly counterstained with hematoxylin and then examined by light microscopy. C-kit and Cx43 positive expression showed dyed light yellow, brown or tan in the membrane and serosa.

\section{Western blot analysis}

Total protein was extracted from the frozen bladder sample. $2 \mathrm{ml}$ of cold cell lysate was added to $0.1 \mathrm{~g}$ of the frozen tissue, and then homogenate was mechanically made. The cell lysate consisted of Tris-cl (pH 7.4) at $10 \mathrm{~mm}$, DTT at $10 \mathrm{~mm}, \mathrm{Nacl}$ at $50 \mathrm{~mm}, \mathrm{NaF}$ at 50 $\mathrm{mm}, 1 \% \mathrm{NP}-40, \mathrm{Na}_{3} \mathrm{VO}_{4}$ at $0.2 \mathrm{~mm}$ (added before use), and Protein inhitor cocktail (added before use). The homogenate was oscillated at $4^{\circ} \mathrm{C}$ for $1 \mathrm{~h}$ and then centrifuged at $12,000 \mathrm{rpm} / \mathrm{min}$ at $4^{\circ} \mathrm{C}$ for 10 $\min$. The supernatant was subpackaged and stored at $-80^{\circ} \mathrm{C}$. Additionally, $50 \mu \mathrm{l}$ of the supernatant was taken for protein concentration determination using a BCA kit. After concentration determination, it was stored at $-70^{\circ} \mathrm{C}$.

After lauryl sodium sulfate-polyacrylamide gel (SDS-PAGE) electrophoreses, the protein was transferred onto the nitrocellulose membrane. The membrane was blocked with skimmed milk, and then incubated with rabbit anti-mouse C-kit and $\mathrm{C} \times 43$ polyclonal antibodies at $4^{\circ} \mathrm{C}$ overnight. After washing, it was incubated with horseradish peroxidase (HRP)-labeled goat anti-rabbit IgG antibodies. Then, biotin-labeled secondary antibody (ready-to-use goat anti-rabbit $\operatorname{lgG}$ ) was added. After washing again, the membrane was DAB-stained. PBS was applied in place of the primary antibodies for negative controls. The internal reference $\beta$ actin was taken for the positive control. Protein molecular weight marker was routinely set before staining. To evaluate the specificity of positive staining, multiple controls were set on the same electrophoresis membrane. Developed films were scanned.

\section{Statistical analysis}

All data were analyzed using SPSS13.0 software. Students' ' $t$ '-tests were used to compare means and $x^{2}$ test were used to compare rates. Analysis of variance was performed for comparisons among groups and Spearman correlation analysis for correlation analysis among parameters. $P<0.05$ was considered statistically significant.

\section{RESULTS}

\section{Mortality}

A high mortality occurred among the spinal cord transected animals. Four rats were dead in the SSCl group and six were dead in the $\mathrm{SCl}$ group. The possible 
reasons might include postoperative infection, urinary retention and intestinal obstruction.

\section{Detrusor leak point pressure}

Compared to the NC group, the leak point pressure in the $\mathrm{SSCl}$ group increased significantly, whereas that in the $\mathrm{SCl}$ decreased significantly $(P<0.01)$. Compared to the NC group, the bladder maximum capacity and compliance in the SSCI group decreased significantly, whereas those in the $\mathrm{SCl}$ group increased significantly $(P<0.01)$.

\section{Minimum tension and contraction frequency}

The minimum tension at the time of contraction occurrence in the SSCI group was $0.262 \pm 0.094 \mathrm{~g}$, which was significantly lower than that in the NC group $(0.675 \pm$ $0.087 \mathrm{~g})$ and the $\mathrm{SCl}$ groups $(0.976 \pm 0.099 \mathrm{~g})$. The contraction frequency under the $1.25 \mathrm{~g}$ preload in the SSCI group was $2.59 \pm 0.13$ times/min, which was significantly higher than that in the NC group $(2.01 \pm 0.26$ times $/ \mathrm{min})$ and the $\mathrm{SCl}$ groups $(0.96 \pm 0.12$ times $/ \mathrm{min})$.

\section{Immunohistochemistry}

The expression of C-kit and Cx43 was shown as light yellow in the membrane and cytoplasma of normal bladder detrusor cells. Brown C-kit and Cx43 expression has been indicated by arrows in the current study. C-kit positive expression was observed in all groups. The numbers at the C-kit positive expression locus in the NC, $\mathrm{SSCl}$ and $\mathrm{SCl}$ groups were $4.50 \pm 1.11,8.30 \pm 1.97$ and $2.20 \pm 1.51$. Compared to the NC group, the C-kit positive expression in the $\mathrm{SSCl}$ group was significantly higher $(P$ $<0.05$ ), whereas that in the $\mathrm{SCl}$ group was significantly lower $(P<0.05)$ (Figure 1). Cx43 positive expression was seen in all groups. The numbers at the Cx43 positive expression locus in the $\mathrm{NC}, \mathrm{SSCl}$ and $\mathrm{SCl}$ groups were $16.21 \pm 1.68,23.50 \pm 1.44$ and $12.63 \pm 1.28$. Compared to the NC group, the Cx43 positive expression in the SSCl group was significantly higher $(P<0.05)$, whereas that in the $\mathrm{SCl}$ group was significantly lower $(P<0.05)$ (Figure 2).

\section{Western blot analysis}

A frozen bladder sample was randomly taken from each group. The single sample was operated repeatedly. As shown in Figures 3 and 4, the relative expression levels of the C-kit protein in the $\mathrm{NC}, \mathrm{SSCl}$ and $\mathrm{SCl}$ groups were $0.43 \pm 0.12,0.71 \pm 0.16$ and $0.26 \pm 0.09$. Compared to the NC group, the C-kit level in the SSCI group increased significantly $(P<0.01)$, whereas that in the $\mathrm{SCl}$ group decreased significantly $(P<0.01)$. The relative levels of the Cx43 protein in the three groups were $0.64 \pm 0.10$, $0.87 \pm 0.06$ and $0.46 \pm 0.04$. Compared to the NC group, the $\mathrm{Cx} 43$ level in the $\mathrm{SSCl}$ group increased significantly $(P<0.01)$, whereas that in the $\mathrm{SCl}$ group decreased significantly $(P<0.01)$.

\section{DISCUSSION}

The pathophysiological procedure of NGB after spinal cord injury is a complicated process, a systemic understanding of which cannot be achieved only through clinic study. Under such a condition, animal models seem to lend particular significance to the task (BieringSorensen et al., 2009; Krogh et al., 2009; Kanai et al., 2011). Till now, scholars have not reached an agreement on whether bladder dysfunction is caused by neurogenic or myogenic factors. Supporters of the neurogenic theory (represented by de Groat) hold that all changes in detrusor excitability stem from neurogenic factors, or are subjected to the continued responses of these factors, which are mainly manifested by an increased number of neuroreceptors and the functional upregulation of neuroreceptors (Theriault et al., 1997; Horvath et al., 2010; Martens et al., 2010), whereas those of the myogenic theory (represented by Brading) maintain that changes in detrusor excitability is caused by both neurogenic and myogenic factors, which include the increased excitability of detrusor cells, enhanced signal transduction function between cells, enhanced association between detrusor cells and ganglion cells etc. (Keirstead et al., 2005; Cronin et al., 2008).

Till now, many studies on NGB have been released. However, most of them are carried out from the neurogenic perspective. Seldom studies focus on the correlation between the secondary change of the detrusor and $\mathrm{DH}$ after neuropathy. The results in the current study showed that the minimum tension at the time of contraction occurrence caused by the mechanic traction in the $\mathrm{DH}$ (also SSCl) group was significantly lower than that in the NC or DA (also SCl) group, and the contraction frequency under the preload of $1.25 \mathrm{~g}$ in the $\mathrm{DH}$ group was significantly higher than that in the NC and DA groups. These results indicate that $\mathrm{SSCl}$ leads to a decrease in detrusor excitation threshold as well as an increase in detrusor excitability. This indication suggests that the occurrence of $\mathrm{DH}$ is closely correlated with an increase in the detrusor excitability after neuropathy.

The possible correlations between the change in detrusor excitability and that in the number of Cajal interstitial cells may include: (1) an increase in the number of Cajal interstitial cells may facilitate the formation of the cell network, which in turn accelerates the electrical signal transduction between cells (as smooth muscle cells are not in a one-to-one correspondence relation with innervation, and meanwhile, synchronic arrival of the 

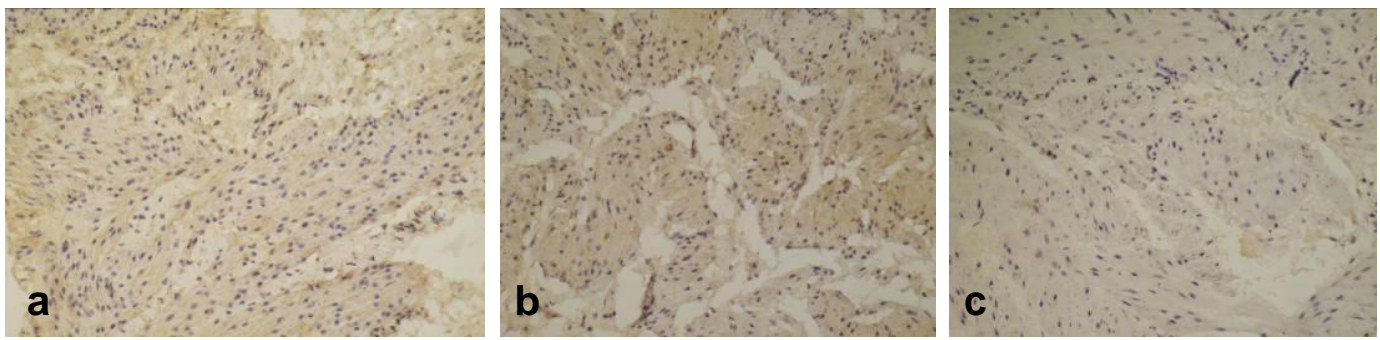

Figure 1. The expression of C-kit in the membrane and cytoplasma of normal bladder detrusor cells ( $\times 400)$. a. Expression of C-kit in NC group, b. Expression of C-kit in SSCI group, c. Expression of C-kit in $\mathrm{SCl}$ group.
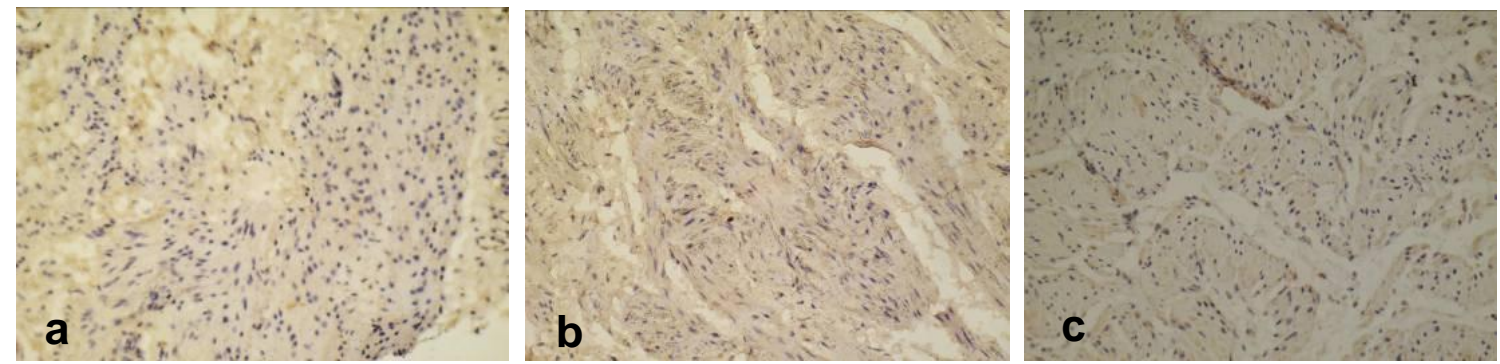

Figure 2. The expression of $\mathrm{C} \times 43$ in the membrane and cytoplasma of normal bladder detrusor cells $(\times 400)$. a. Expression of $\mathrm{Cx} 43$ in NC group, b. Expression of $\mathrm{Cx} 43$ in $\mathrm{SSCl}$ group, c. Expression of $\mathrm{Cx} 43$ in $\mathrm{SCl}$ group.

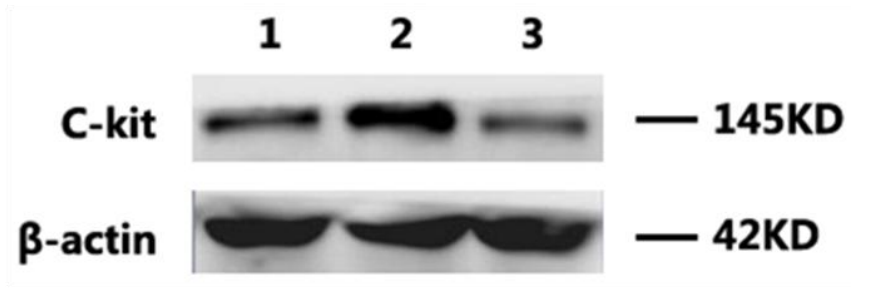

Figure 3. Detection of the C-kit expression using Western blot analysis. 1. NC group, 2. SSCl group, 3. SCI group.

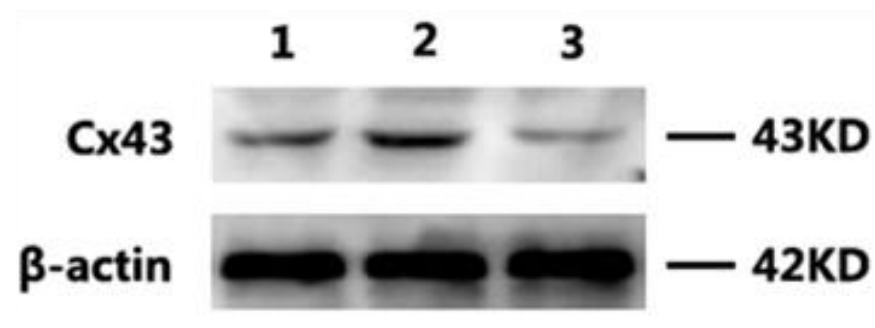

Figure 4. Detection of the Cx43 expression using Western blot analysis. 1. NC group, 2. E SSCI group, 3. SCI group.

action potential signals at each cell is the prerequisite for the synchronic contraction of multiple smooth muscle cells, a more developed Cajal interstitial cell network promotes the electrical signal transduction), and (2) as Cajal interstitial cells have the potential to produce spontaneous excitations, the local spontaneous discharge increases with the increase in the number of Cajal interstitial cells, and when the spatial summation of the discharge reaches the threshold potential of the smooth muscle, it will trigger the smooth muscle's contraction (Yamamoto et al., 2001; Erol et al., 2009).

Gap junctions are the pathway for excitation transduction between detrusor cells. The current study showed that the expression of $\mathrm{Cx} 43$ in the detrusor cells increased after SSCl. The increased Cx43 expression helps ions and charged micromolecules pass through the junction pathway faster; these substances depolarize the flanking cell membranes to form extensive electrical coupling and facilitate the electric transduction between cells, which in turn make easier the transmission of electric activity among local cells to the whole bladder leading to uninhibited contractions of the bladder under a subjective control-free condition (Gabella, 1997). In addition, a characteristic of innervation in the bladder is that a nerve terminal dominates multiple detrusor cells rather than in a one-to-one correspondence relation; for a single detrusor cell, it generates a contractile response through excitation contraction coupling after an excitation; but, as $\mathrm{DH}$ is the phenomenon of the whole bladder contraction after an excitation, it has to resort to a special transduction mechanism; this is where the gap junctions play a role (Bramich and Brading, 1996; Watanabe et al., 
1997).

Therefore, from the perspective of excitation transduction, SSCI induces an increase in gap junctions between detrusor cells to promote the occurrence of $\mathrm{DH}$. This gives a further support for the myogenic theory about changes in the bladder function. The results in this study show that after SSCI, detrusor fibrosis compliance decreases; secondary changes in the detrusor happened. Gap junctions increased in number and the excitation conduction between cells strengthened. These myogenic changes in detrusor may also play an important role in causing NGB, apart from neural factors.

Spinal cord injury-induced NGB severely impairs patients' health, and most patients die of kidney failure due to bladder high pressure. Till now, satisfactory progress has not been achieved for the clinical control of this condition. Study on detrusor stimulation-caused contraction function regulation from the myogenic perspective may offer data for evolving better therapeutic approaches to benefit bladder function protection and recovery.

\section{ACKNOWLEDGMENTS}

This study was supported by Program for Liaoning Excellent Talents in University (LNET).

\section{REFERENCES}

Biering-Sorensen F, Craggs M, Kennelly M, Schick E, Wyndaele JJ (2008). International urodynamic basic spinal cord injury data set. Spinal Cord 46:513-516.

Biering-Sorensen F, Craggs M, Kennelly M, Schick E, Wyndaele JJ (2009). International urinary tract imaging basic spinal cord injury data set. Spinal Cord 47:379-383.

Bramich NJ, Brading AF (1996). Electrical properties of smooth muscle in the guinea-pig urinary bladder. J. Physiol. 492:185-198.
Cronin M, Anderson PN, Cook JE, Green CR, Becker DL (2008). Blocking connexin43 expression reduces inflammation and improves functional recovery after spinal cord injury. Mol. Cell Neurosci. 39:152-160.

Erol B, Kocak T, Kadioglu A, Müslümanoğlu L, Karamehmetoğlu S, Akinci M, Arikan $F$ (2009). The relationship between level of injury and bladder behavior in patients with post-traumatic spinal cord injury. Ulus Travma Acil. Cerrahi. Derg. 15:377-382.

Gabella G (1997). Cells and cell junctions in the muscle coat of the bladder. Scand. J. Urol. Nephrol. Suppl. 184:3-6.

Horvath EE, Yoo PB, Amundsen CL, Webster GD, Grill WM (2010). Conditional and continuous electrical stimulation increase cystometric capacity in persons with spinal cord injury. Neurourol. Urodyn. 29:401-407.

Kanai A, Zabbarova I, Ikeda Y, Yoshimura N, Birder L, Hanna-Mitchell A, de Groat W (2011). Sophisticated models and methods for studying neurogenic bladder dysfunction. Neurourol. Urodyn. 30:658-667.

Keirstead HS, Fedulov V, Cloutier F, Steward O, Duel BP (2005). A noninvasive ultrasonographic method to evaluate bladder function recovery in spinal cord injured rats. Exp. Neurol. 194:120-127.

Krogh K, Perkash I, Stiens SA, Biering-Sørensen F (2009). International bowel function extended spinal cord injury data set. Spinal Cord 47:235-241.

Martens FM, van KHJ, Beekman JA, Rijkhoff NJ, Heesakkers JP (2010). Limited value of bladder sensation as a trigger for conditional neurostimulation in spinal cord injury patients. Neurourol. Urodyn. 29:395-400.

O'Carroll SJ, Alkadhi M, Nicholson LF, Green CR (2008). Connexin 43 mimetic peptides reduce swelling, astrogliosis, and neuronal cell death after spinal cord injury. Cell Commun. Adhes. 15:27-42.

Pannek J, Stohrer M (2008). A proposed guideline for the urological management of patients with spinal cord injury. BJU. Int. 102:516518.

Theriault E, Frankenstein UN, Hertzberg EL, Nagy JI (1997). Connexin43 and astrocytic gap junctions in the rat spinal cord after acute compression injury. J. Comp. Neurol. 382:199-214.

Watanabe T, Omata S, Lee JZ, Constantinou CE (1997). Comparative analysis of bladder wall compliance based on cystometry and biosensor measurements during the micturition cycle of the rat. Neurourol. Urodyn. 16:567-581.

Yamamoto T, Ghosh R, De Groat WC, Somogyi GT (2001). Facilitation of transmitter release in the urinary bladders of neonatal and adult rats via alpha1-adrenoceptors. Eur. Pharmacol. 414:31-35. 